\title{
Industrial processing technologies for insect larvae
}

\author{
D. Sindermann ${ }^{1 *}$, J. Heidhues ${ }^{1}$, S. Kirchner ${ }^{2}$, N. Stadermann ${ }^{3}$ and A. Kühl ${ }^{3}$ \\ ${ }^{1}$ GEA Westfalia Separator Group GmbH, Process Technology and Innovation, Renewables, Chemicals E Pharma, Werner- \\ Habig-Str. 1, 59302 Oelde, Germany; ${ }^{2}$ GEA Westfalia Separator Group GmbH, Business Line Renewables, Werner-Habig- \\ Str. 1, 59302 Oelde, Germany; ${ }^{3}$ Maschinenfabrik Reinartz GmbH E Co. KG, Industriestraße 14, 41460 Neuss, Germany; \\ dirk.sindermann@gea.com
}

Received: 17 August 2020 / Accepted: 17 December 2020

(c) 2021 Wageningen Academic Publishers

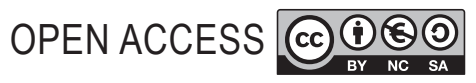

TECHNICAL REPORT

\begin{abstract}
For an economic production of safe and standardised products from commercially reared insects larvae for food and feed, industrial processing technologies for insects processing are needed. Protein meals for feed and food produced from insect larvae typically vary in fat content. Main factors influencing the fat content are the individual species, the substrate feed during rearing and the time of harvest. However, feed and food industry are looking for standardised products which can be adjusted to the customers' specifications. Separation technologies to recover insect fat and thereby reduce the residual fat content in the dry meal have been adopted from familiar applications and have been further developed for insect larvae de-fatting. Two major process technologies that are used for industrial applications are discussed in this technical report: dry and wet processing. In comparison, both technologies have their individual advantages depending on the individual application and properties aimed for. Since these processes for lipid separation are joint processes not only low-fat meal is recovered but also lipids recovered can add value as an additional product. In addition, chitin can be separated to increase the protein content in the larvae meal and add value as biomaterial for further processing, e.g. production of chitosan. Moreover, automation and cleaning of complete process lines are important considerations. Especially for future food applications.
\end{abstract}

Keywords: insect larvae, processing technology, lipids, protein, chitin, mechanical separation, drying, processing steps, processing stages, devitalisation, grinding, cleaning, automation

\section{Introduction}

With the expected increasing demand in food and feed, insects' leading to upscale insect production and increasing commercialisation, industrial insects larvae processing becomes more and more important for the economic production of safe and standardised products from commercially reared insects larvae for food and feed. This technical report gives an overview of the most important processing technologies and machines for recovering protein enriched meal and insects lipids from insects larvae derived from industrial insect farming. Chitin removal as a tool to increase the proportion of digestible protein in the meal is also discussed. The technologies outlined regarding processes and machinery for insects processing are mainly based on relevant industrial experience and perspective. Therefore, in this overview it is focussed on reference plants that are currently being tested or delivered in the insect industry or that have high 'technology readiness levels' (TRL) (European Commission, 2019) based on experience from very familiar applications. Processing of rearing residues is not covered in this overview.

Regarding the process technologies for insect meal and lipids recovery the important process stages for the two different technologies dry and wet processing are presented and discussed. To outline and clearly distinguish each individual process, it is focussed on differences in mechanical separation and typical drying technologies used for the two processes. 


\section{Motivation for insect larvae processing}

Several publications about the benefits of insect larvae reared in industrial vertical farming systems to recover high value meal for feed and food have been published (De Jong, 2018; Halloran and Vantomme, 2013; Van Huis and Tomberlin, 2017; Van Huis et al., 2013). For some applications the whole larvae are dried and sold as feed and sometimes food. For other applications there is a need to disintegrate the whole larvae and dry the product to recover a meal and therefore remove most of the water and retain all other ingredients of the raw material. This is a simple process and is especially interesting for startups entering meal markets. Disadvantageous is a relatively high fat content and therefore lower protein content. Also, transportation and storage are more difficult for meals high in fat. Higher fat contents in solids to be dried also limit the choice of suitable dryers since the fat contend in the meal can be a selection criterion for the type of dryer used.

For all these reasons, an economic removal of a significant amount of lipids from the insect larvae is considered by industrial insect meal producers. Because of a joint process, insect lipid is recovered as a separate phase which can add value to the process beside obtaining a meal containing a higher amount of protein. In some cases, the chitin fraction can also be separated and recovered as fraction for further processing (Section 7).

Common processes used in practice are derived from traditional technology for comparable applications like processing of animal by-products (Düpjohann, 1991) or fish (GEA, 1999). It is important to factor in legal requirements and regulations that are varying between regions and countries regarding the use of insect meal and derived insect lipid fractions in feed and food. This affects the use of meals and lipids for feed and especially food applications. For example, regulatory challenges are limiting the use of separation technologies when it comes to protein meal for food applications in many regions, e.g. the European Union (IPIFF, 2018). Figure 1 gives an overview over different potential insect applications and products that could be obtained by using different processing technologies.

For de-fatting insect larvae, different process technologies can be applied. In this overview the focus is on the industrial perspective for the two main processing pathways used: dry and wet processing. Therefore, not all theoretically possible approaches are discussed, but only relevant and economically feasible technologies based on practical experiences made within the insect industry and familiar industries are presented.

\section{Devitalisation}

Legal requirements and animal welfare aspects must be considered before larvae received from insect farming can be further processed (IPIFF, 2019). Effective and efficient killing of living larvae for further processing can be achieved with various systems. For dry processing (Section 4) devitalisation is often conducted by steaming. Depending on the type of dryer used for this process, steaming is performed in a separate chamber before the dryer or directly inside a chamber of the dryer. With such a steaming step, the International Platform of Insects for Food and Feed's (IPIFF) recommendations regarding insect welfare are fulfilled. At the same time steaming increases the efficiency of the drying process significantly.

Alternatively, hot water $\left(\mathrm{T}>90^{\circ} \mathrm{C}\right)$ is applied for a rapid devitalisation. For wet processing this method has been applied using tanks for small batch processes or heat exchangers for continuous processing. When using double wall tubular heat exchangers, processing in closed systems allows efficient 'cleaning-in-place' (Section 5 'Cleaning'). This is relevant for food grade wet processing. Typically, larvae are pumped through the heat exchanger with hot water added at the feeding pump. Screening systems (e.g. vibrating screens; Figure 2) are used to remove most of the water after the devitalisation step. To safe or recycle water and recover heat, water is collected and recirculated to the feeding pump.

Insect devitalisation by hot water is not only essential for insect welfare purposes but also has advantages regarding end product qualities when applying this step. For example, the de-activation of own insect enzymes reduces the 'browning effect' of the larvae significantly. Devitalisation with hot water has proven to reduce typical browning when processing larvae (Heidhues et al., 2020). Another positive effect of using hot water for devitalisation is a reduction of surface contamination due to washing the larvae before further processing (Rumpold et al., 2017). This results in a reduced ash content and therefore increased protein content. Since devitalisation with hot water is resulting in some water absorption or uptake (approx. 5-10\%) of the insects, it is more appropriate for wet processing (Section 5).

\section{Dry processing technologies}

The major feature of dry processing is a drying step to remove most of the moisture of the insect larvae prior to the mechanical separation of lipids.

This important difference to wet processing (Section 5) not only has an impact on operational costs and capital expenditure (Schmidt, 2019), it is also influences product qualities of the different fractions recovered (Böschen, 2018). Sometimes this process is also referred to as 'high 


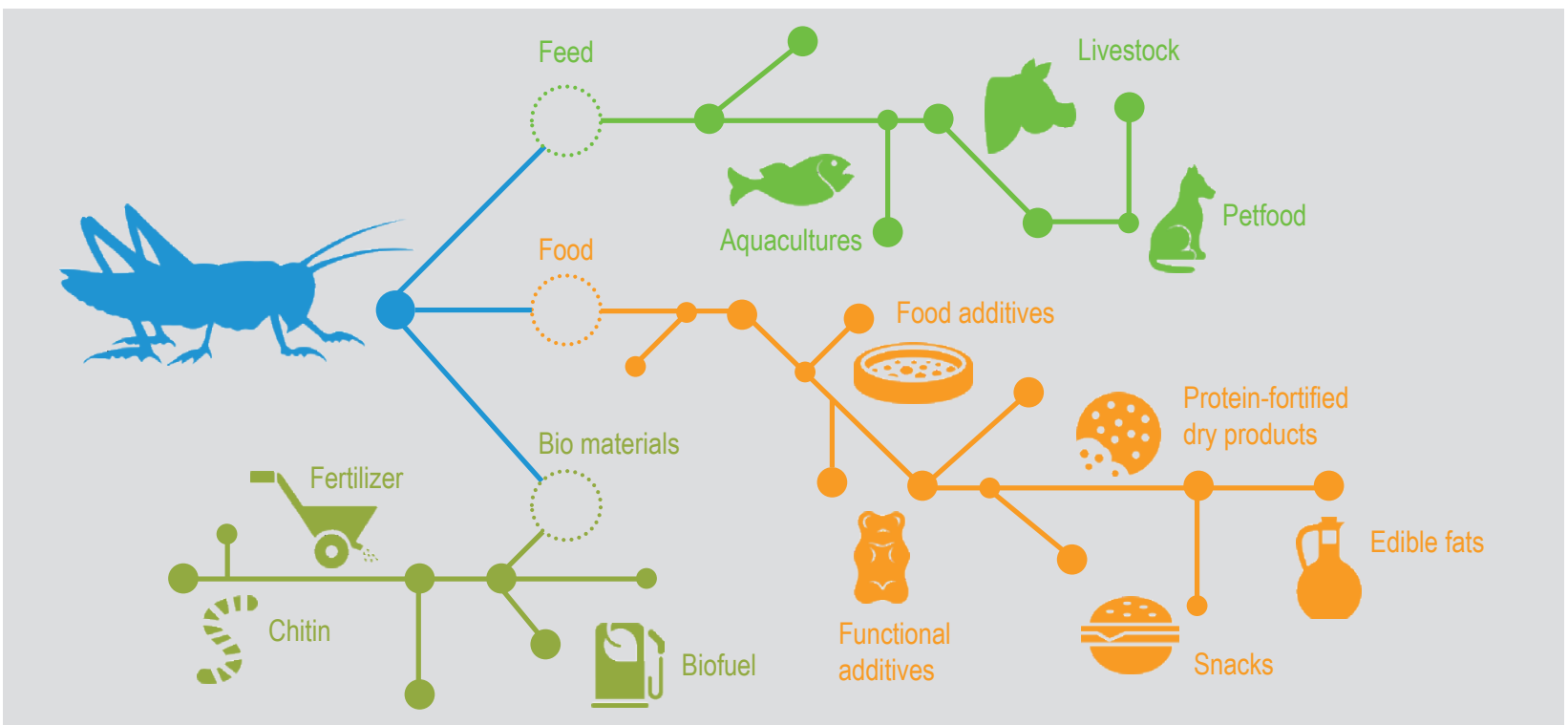

Figure 1. Potential applications upon processing insect larvae for food, feed and bio materials (Sindermann, 2019b).

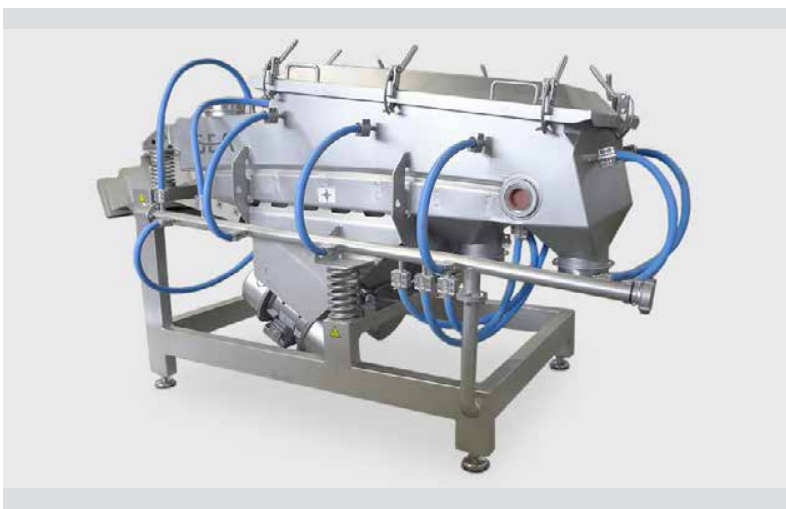

Figure 2. Vibrating screen (photo by GEA Scan-Vibro A/S, Svendborg, Denmark).

temperature process' when dryers with higher drying temperatures above $100^{\circ} \mathrm{C}$ are used. Even at temperatures around $80{ }^{\circ} \mathrm{C}$ and retention times of approx. $30 \mathrm{~min}$, temperatures and retention times are high enough to meet IPIFF guidelines for safe products (IPIFF, 2018). In some publications the process is referred to as 'screw press process' because of the press used in the lipid separation stage (Section 4 'Lipid separation').

\section{Drying}

Different types of dryers can be used for drying of insects, that cannot all be presented here. In this overview, three exemplary dryer types with a larger practical relevance are discussed in more detail. These three, totally different types can also be used to dry wet solids in the wet processing pathway described in Section 5.

\section{Disc dryer}

Contact dryers such as a disc dryer are the most popular dryers used for comparable purposes. In many fish oil plants or high temperature rendering plants to recover animal fats, disc dryers are common. Depending on the required throughput of insect larvae to be dried, different systems for batch or continuous operations can be utilised. Economic aspects also have to be taken into consideration.

The larvae entering this type of contact dryer are dried by rotating steam-heated discs welded on a central shaft (Figure 3). These discs increase the total contact area for larvae inside the dryer and apply indirect heat over a larger area in a relatively compact design. Larvae are pushed through the dryer from one end to the other. Paddles on the edges of the rotating discs agitate the larvae and support the movement through the dryer towards the discharge outlet. Typically, vapour is collected in an exhaust gas hood and discharged via an exhaust gas pipe towards a condensation system. The wet exhaust gases can be fully condensed or further treated in an air washing system. Heat recovery systems are recommended to make insect processing more efficient and environmentally friendly.

Product qualities are strongly influenced by process temperatures applied (Kröncke et al., 2018). If meals with high functionality and meals and lipids with light colour are required vacuum drying configurations are also available for disc dryers.

Disc dryers can also be used to dry whole larvae without further de-fatting. But the size of the whole larvae will be reduced using disc dryers. If the original structure needs 


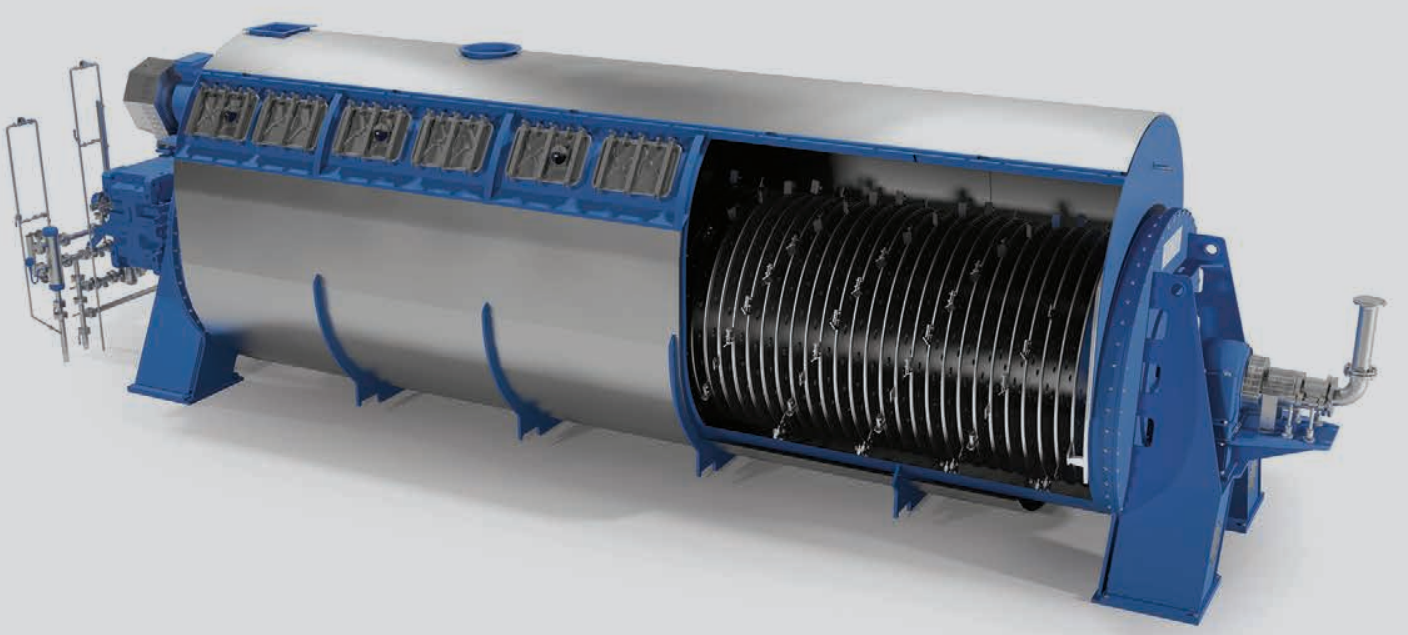

Figure 3. Typical disc dryer for continuous drying (Haarslev, 2020).

to be maintained other dryers need to be selected like fluid bed dryers, microwave dryers or ring dryers.

\section{Fluidised bed dryer}

In contrast to contact driers such as the disc dryer, fluidised bed dryers belong to the group of air dryers. Insect larvae processed in a fluidised bed dryer float on a cushion of air. Heated (or cooled) air is flowing through the product against gravitation creating a fluidised bed. Process air is supplied to the bed through a perforated distributor plate and flows through the bed of solids at a sufficient velocity to support the weight of particles in a fluidised state. Bubbles form and collapse within the fluid bed of material promoting intense particle movement. In this state the solids behave like a free-flowing boiling liquid. Very high heat and mass transfer rates are obtained as a result of the intimate contact between individual particles and the fluidising gas (GEA, 2020b).

A special feature of this type of drying are individual drying zones where insect larvae can be dried to the required residual moisture content in a gentle way. For insect larvae processing, because of the effect of temperature and time to the protein quality, cooling after drying is recommended. The drying and cooling section can be two separate units or can be combined in one unit where approx. two third of the process chamber are needed for drying and the remaining length is used for cooling the larvae right after drying.

As illustrated in Figure 4 beside the drying and cooling chambers additional equipment for drying and cooling air treatment and equipment for exhaust air treatment including dust removal are required making this dryer more complex.
With fluidised bed dryers moist particles can be dried at defined temperatures to achieve a specified residual moisture. Evaporation of large quantities of water is possible in a relatively short period of time and under homogeneous and gentle drying conditions.

For the insect industry another advantage is the flexible use for other end products like drying complete unprocessed insect larvae for food and feed markets. In contrast to disc dryers the shape of larvae is retained. This also applies to microwave dryers described in the following subchapter.

\section{Microwave dryer}

In drying insect larvae microwave drying is a direct heating method and an alternative method (Leanarts et al., 2018) with several units already installed for insects drying.

In the rapidly alternating electric field generated by microwaves, polar materials orient and reorient themselves according to the direction of the field. The rapid changes in the field cause rapid molecular reorientation of dipoles, resulting in friction and heat. For example at 2,450 MHz, the orientation of the field changes 2,450 million times per second. Different materials have different properties when exposed to microwaves, depending on the extent of energy absorption, which is characterised by the loss factor (Van den Bossche and Van Vaerenbergh, 2014).

Microwave dryers as depicted in Figure 5 are ready for operation quickly and provide a relatively short drying time with an evenly distributed energy input and well controlled drying process. Because of this energy can be saved and good organoleptic properties of the dried larvae can be achieved. 


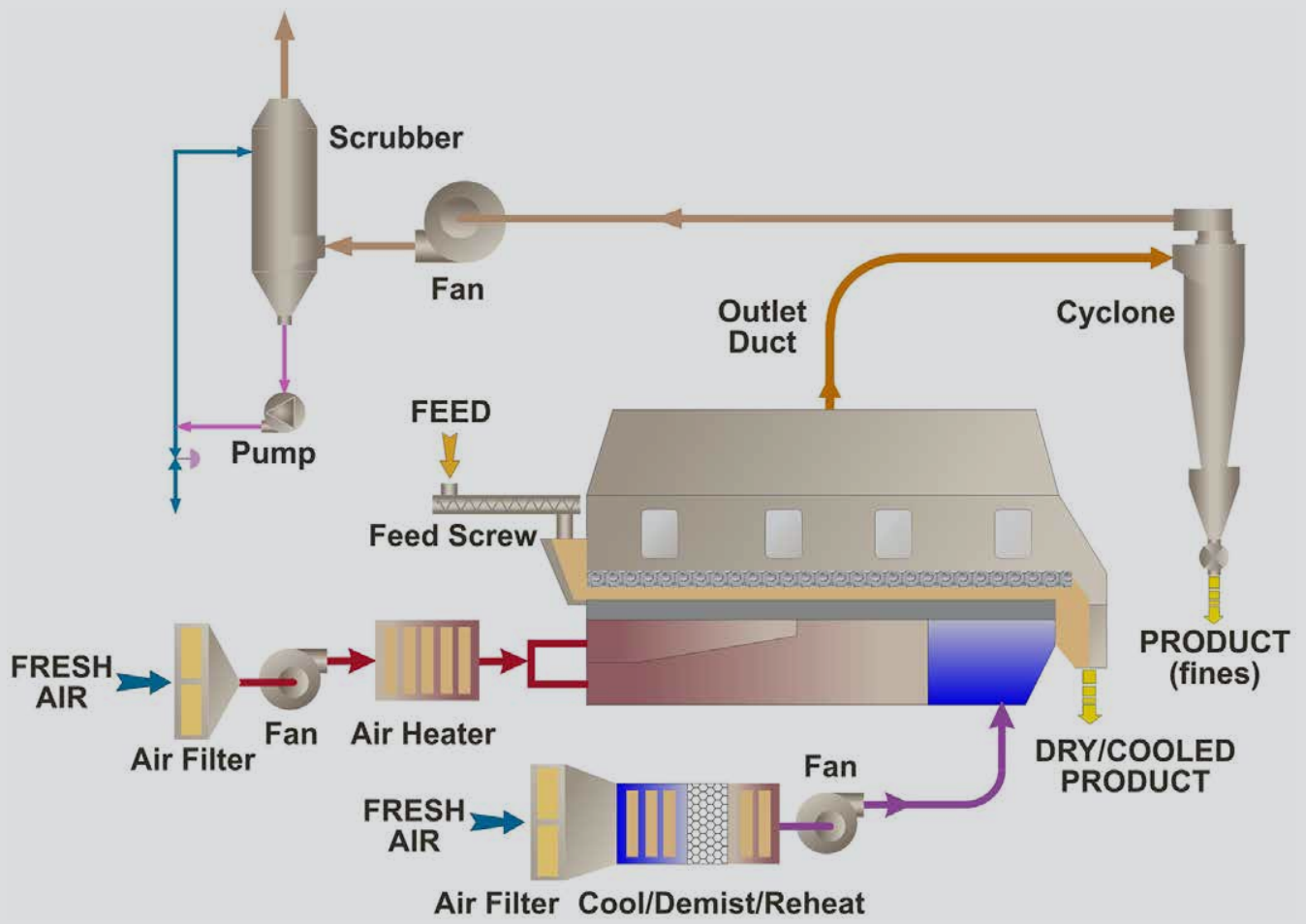

Figure 4. Principle of fluid bed dryer including heating and cooling section (GEA, 2020b).

While many conventional drying systems especially for smaller capacities often work as a batch dryer microwave drying is suitable for continuous drying of the insect larvae passing a drying tunnel via a conveyor belt.

\section{Lipid separation}

Fat and protein content of insect larvae depend strongly on species, substrate fed and developmental stage at time of harvest (Rumpold et al., 2017). Typical fat contents vary e.g. for black soldier fly (BSF) larvae between 7 and $39 \%$ based on total larvae weight (Barragan-Fonseca et al.,
2017). Protein recovery from insect larvae is always a joint process, i.e. low-fat meal and consequently high protein products require an effective de-fatting stage. In addition, the separated lipid fraction can contribute to the added value of insect larvae processing.

An important process stage for dry processing is the mechanical de-fatting step by a screw press (Figure 6) pressing the dried insect larvae.

For BSF it is recommended to condition the product before the mechanical defatting. Target is to reach a product
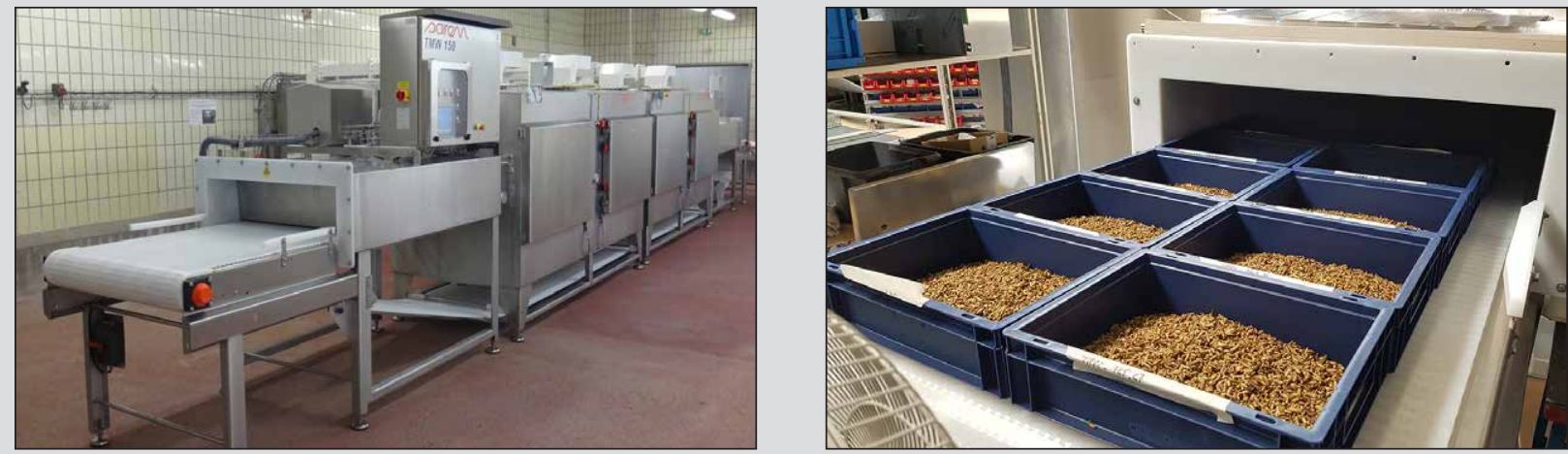

Figure 5. Continuous microwave dryer for insect larvae (pictures by Sairem, Décines-Charpieu, France). 


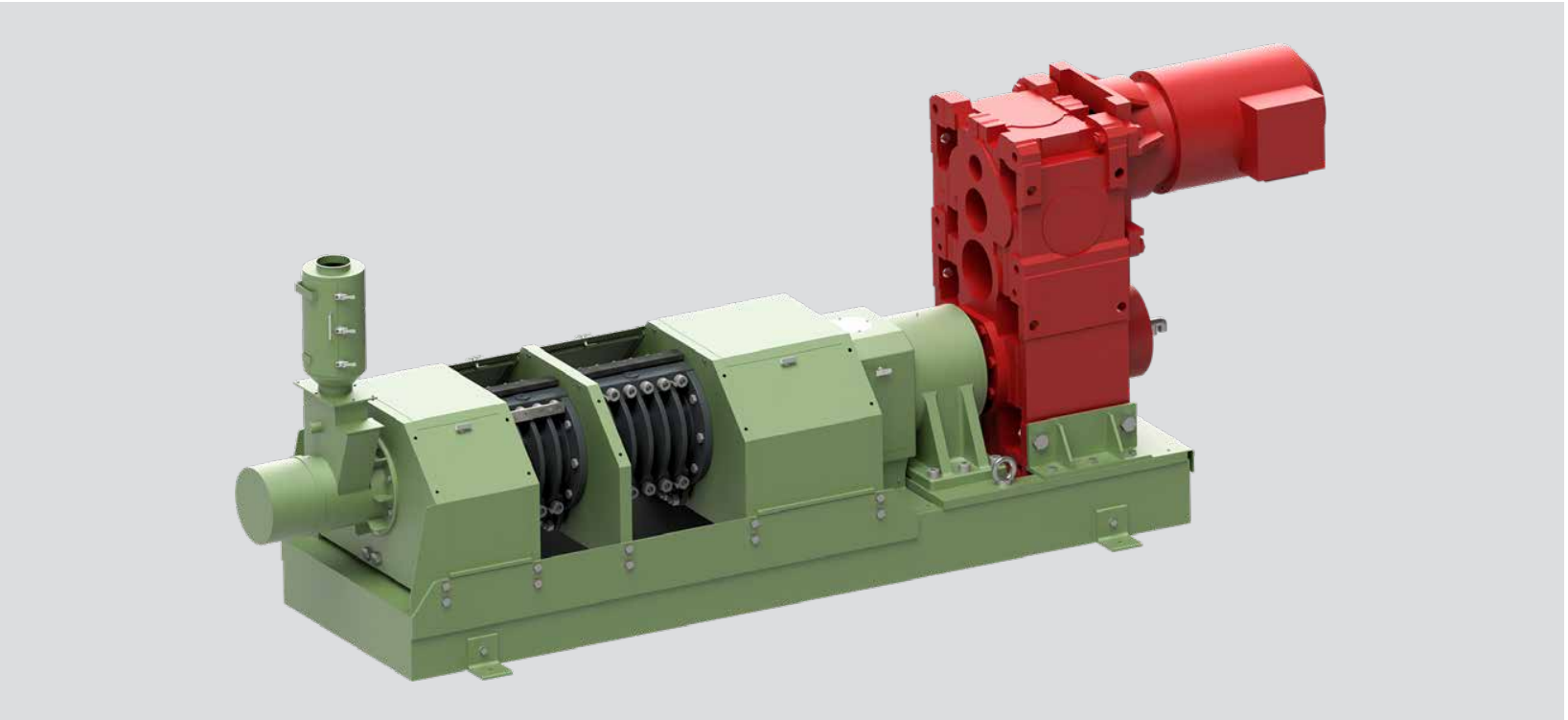

Figure 6. Screw press for insect larvae de-fatting (Reinartz, 2020).

temperature, which is above the fat melting temperature, before the product gets pressed. This increases the efficiency of the press process and can be performed by using a process screw or a so-called heating cattle. The heat transfer is typically regulated via sensors and controllers.

Inside the screw press the insect larvae are exposed to increasing compression at the different process phases. During the first compression phase without liquid discharge, cells of the larvae are disrupted, and air can escape from hollow spaces. De-fatting takes place during the following compression stage while the pore volume is reduced, and lipids are released. After lipid separation the press cake can be formed into pellets or chips depending on specific requirements. For insect processing optimised presses are available reducing the residual fat content to approx. $6 \%$ due to a special geometry of the screw. Screw presses with temperature-controlled screw shaft for heating or cooling are available for insects processing. Additional heating improves the de-fatting process and cooling might be required if focus is retaining the functionality of the proteins in the meal. Since the lipid fraction is mainly consisting of fat, which solidifies at ambient temperature, so-called heat able pillow plates inside a fat discharge chamber keep the lipids collected in a liquid state. In combination with a fat conveying screw the discharge of the viscous fat can be controlled.

\section{Further processing of defatted insect meal}

\section{Meal cooling}

The insect press cake discharged from the screw press should be cooled after pressing to reduce an impact on protein quality and storage stability. This can be achieved with ambient air in an open evaporation screw or inside a counter current heat exchanger. Immediate subsequent cooling reduces thermal impacts on amino acid chains and therefore improves storage stability (Baltes and Matissek, 2011)

\section{Meal grinding}

After pressing, the press cake recovered by the screw press needs further milling to reduce its particle size based on individual requirements of the end customer. Typical particle sizes are approx. $1 \mathrm{~mm}$ but can be larger depending on intendent applications e.g. a more granular structure for pressing pellets for aquaculture feed.

The milling step to insect meal after the screw press pressing step typically takes place in impact crushers, flake crushers or hammer mills that are not described in detail here.

\section{Lipid clarification}

Lipid recovered after de-fatting of the insect larvae needs to be clarified to become a value-added product in addition to the obtained de-fatted protein-enriched insect meal. Different solutions for different plant sizes and customer requirements are available that are based on technologies used e.g. for vegetable oil or animal fat recovery.

\section{Static sedimentation}

For smaller quantities to be processed static sedimentation systems (Figure 7) might considered. Lipids recovered by the screw press are collected in heated sedimentation tanks for liquid clarification. After 5 to 7 days the clarified liquid is discharged by floating from the middle section 


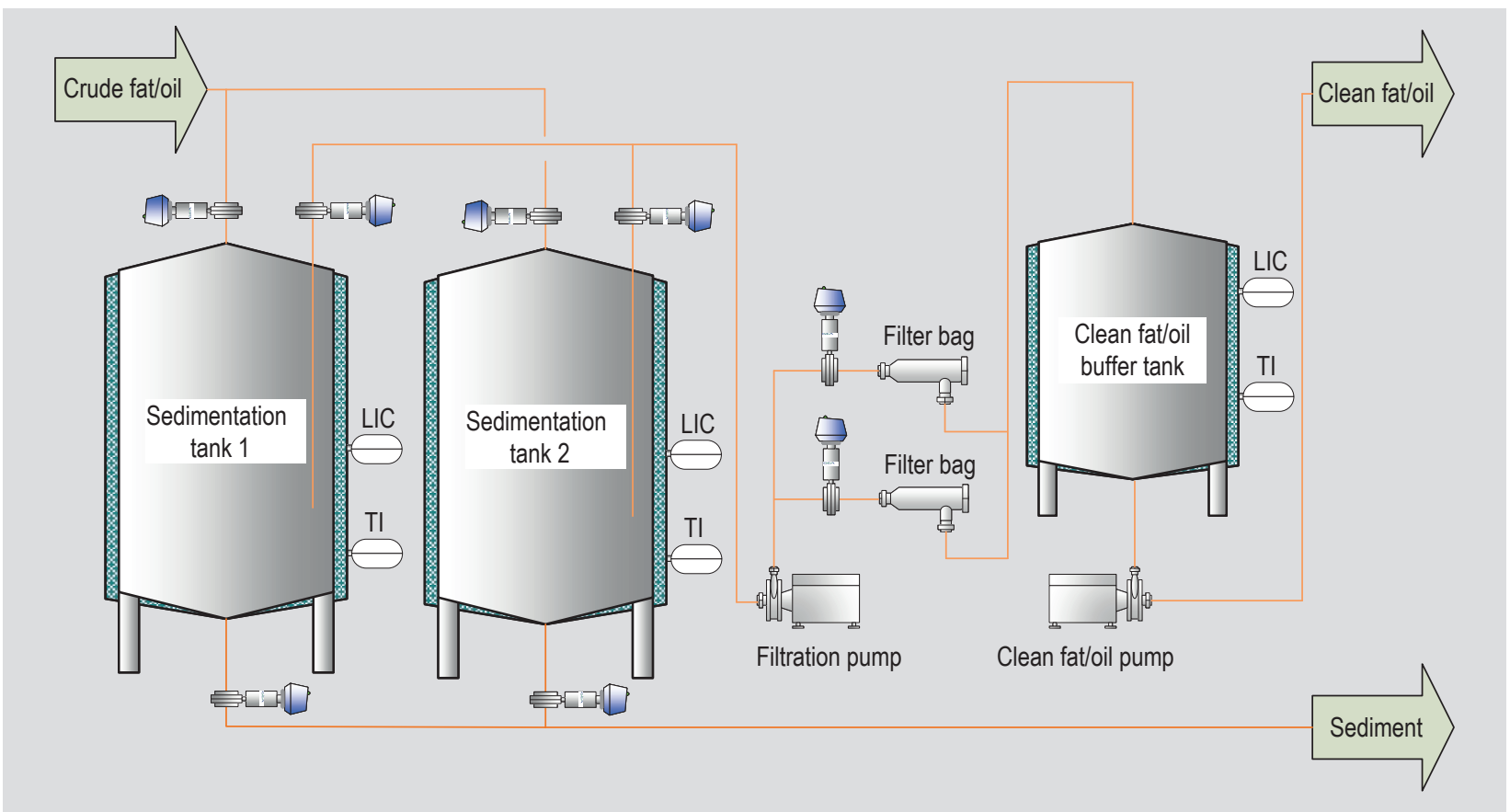

Figure 7. Example for static separation system (figure by GEA Westfalia Separator GmbH, Oelde, Germany).

of the tank. Remaining floating particles are removed by filter bags, which the fat is passing before it is collected in the clean fat tank. Sedimented solids are drained from the bottom. Despite relative low capital and operational expenditure for such systems long retention times of the lipids being in contact with residual moisture and solids might result in higher free fatty acid contents reducing the quality of the fat recovered.

\section{Filters}

Filter systems offer much quicker clarification overcoming the disadvantages of the static separation system using sedimentation tanks. Depending on the quantities of lipids to be clarified different filter designs should be considered. Two examples suitable for lipid clarification within dry processing systems are filter chamber presses (Figure 8) and vertical pressure leaf filters (Figure 9).

Filter Chamber Presses are mainly used for small and medium-sized production capacities. Raw fat discharged from screw presses is collected in heatable supply tanks to store the lipids in front of the discontinuous and semiautomated filter system. Filter plates can be mantled with specific filter cloths according to insect fats and specific solids content in the fat. These cloths hold back solids in different layers during filtration. The growing layer of solids collected is causing a self-filtering layer, so that no other filtration aids are required. Depending on the design of the filter, the collected filter cake can be recirculated to the screw press.
As mentioned, another example for filters used in dry processing systems to clarify recovered lipids are vertical pressure leaf filters. These filters can be used for larger capacities of insect lipids to be clarified. Like for other clarification stages a heatable storage tank upstream of this filter system is required. The filtration process can be fully automated. Only for cleaning, filter leafs need to be removed depending on the solids load of the lipid after pressing.

\section{Clarifying decanter centrifuge}

Centrifuges are commonly used in familiar applications like processing of animal by-products, fish meal plants or vegetable oil plants to clarify fats and oils separated by screw presses. For medium and larger processing lines centrifuges for continuous clarification of lipids from the pressing stage can be used for fully automated clarification and high flexibility if process conditions are changing.

A clarifying decanter as shown in Figure 10 is a horizontal screw centrifuge separating liquids from insoluble solids. The suspension from the liquid discharge of the press (Section 4 'Lipid separation') is fed into a relatively fast rotating cylindroconical bowl via an inlet tube. Clarification of insect fat takes place according to differences in density. Inside the rotating bowl the heavy solids are collected at the bowl shell. The lighter liquid phase is separated as a liquid ring above the solids and is collected continuously at the liquid discharge (Hamatschek, 2016). A conveying scroll rotating at a differential speed slightly faster than bowl speed is conveying the collected solids out of the turning 


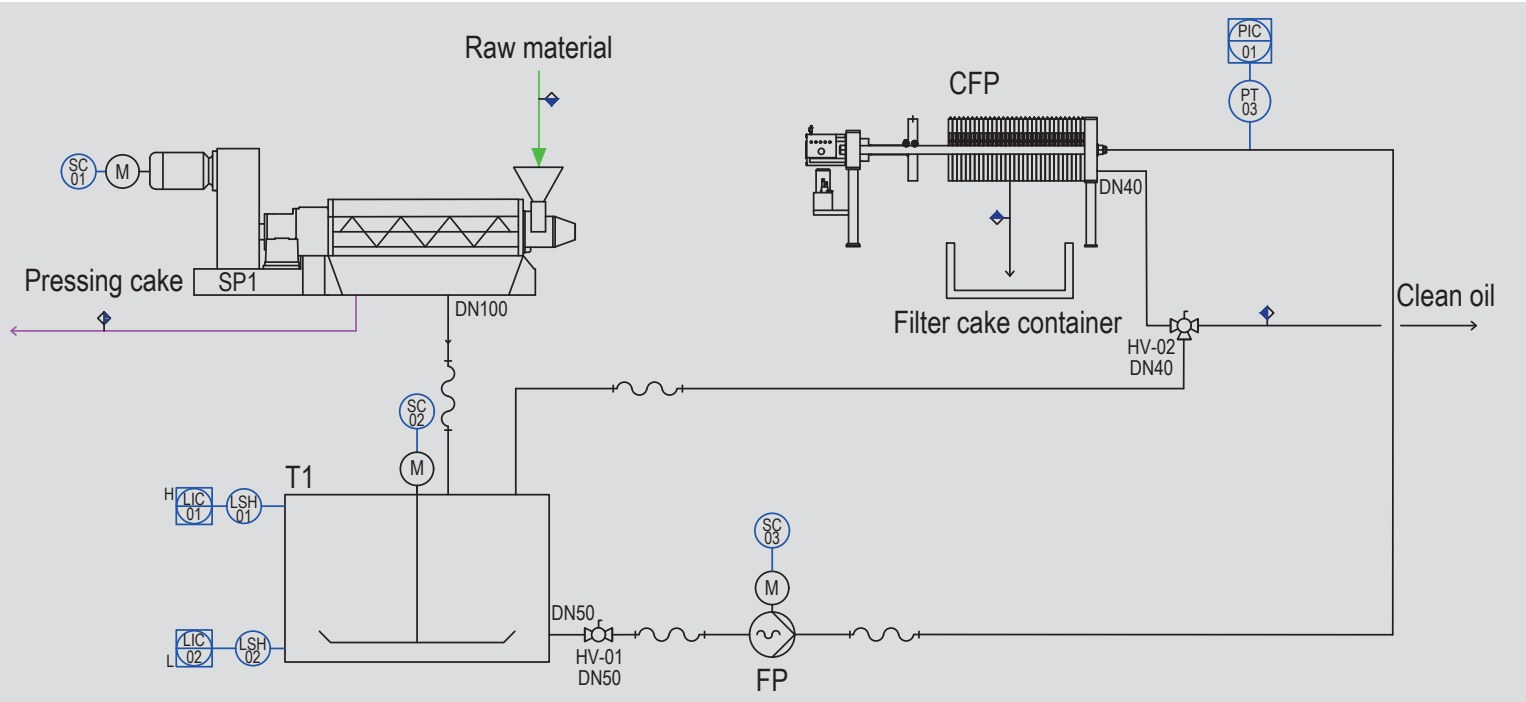

Figure 8. Filter chamber press (figure by Maschinenfabrik Reinartz GmbH \& Co. KG, Neuss, Germany).

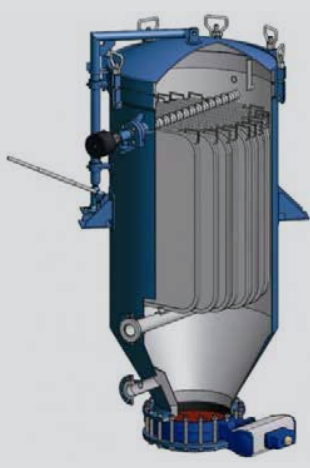

Figure 9. Vertical pressure leaf filter (M Miles Global, 2020). bowl towards solids discharge ports. In dry processing these solids can be recirculated into the feed of the screw press.

The right bowl and scroll design in terms of geometry, material and wear protection needs to be adapted for optimal clarification of insect lipids. For example, a flatter cone angle helps to convey fine and relatively light solids out of the bowl against acting centrifugal forces more easily.

Most designs allow a large flexibility regarding process variations. Relatively high solids loads can be processed with clarifying decanters (Hamatschek, 2016). This

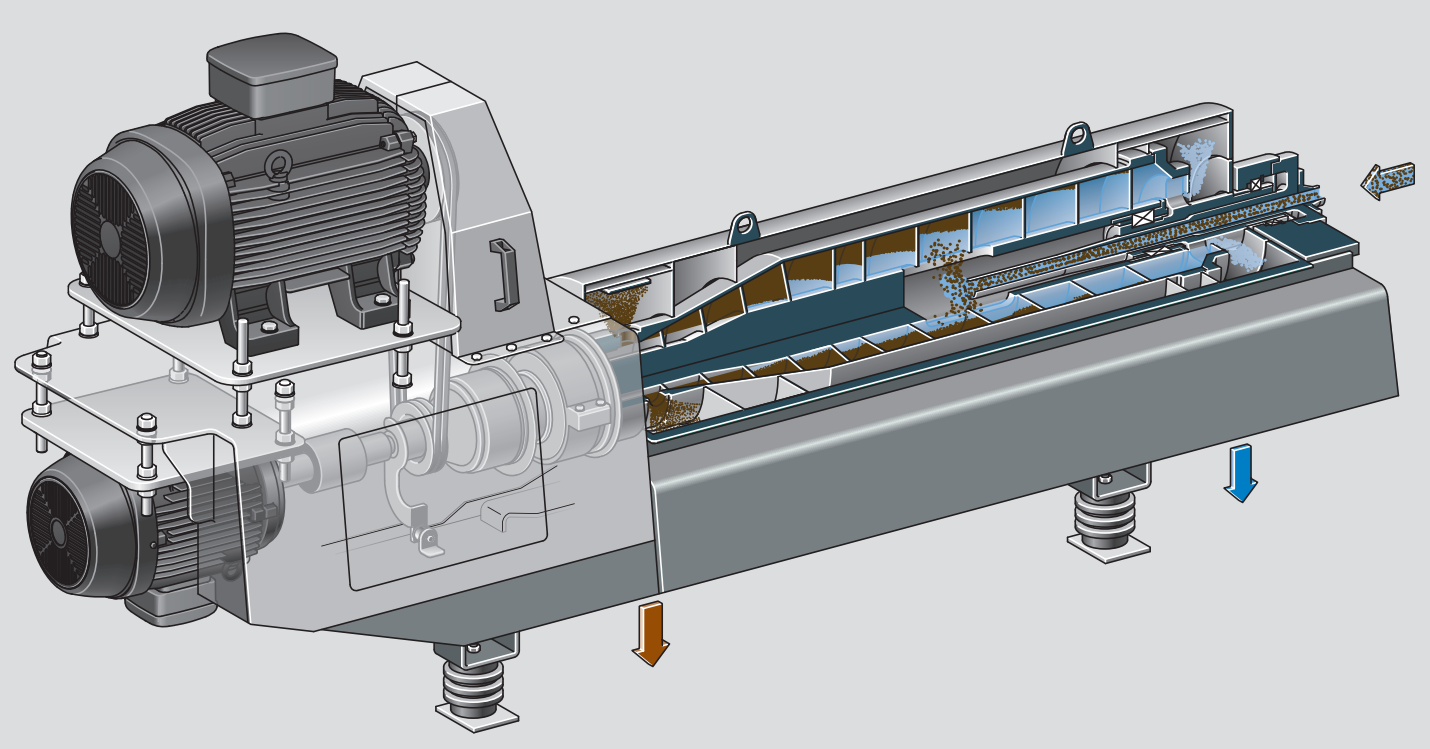

Figure 10. Clarifying decanter: Suspension (lipids discharged from press in dry processing) is fed into rotating bowl and separated into solids (brown arrow) and liquid (blue arrow) phase (figure by GEA Westfalia Separator GmbH, Oelde, Germany). 
allows operators to change parameters of the screw press independently from the downstream lipid clarification. With modern systems bowl and differential speed can be adjusted according to changing throughput capacities or solids loads of suspensions to be clarified and therefore reducing energy costs, wear-and-tear if the maximum capacity is not required based on a specific production situation. In order to find an optimum clarification of the insect lipids and optimum de-fatting of the solids separated, decanters can be adjusted in terms of the liquid discharge diameter and therefore the resulting drying zone for the solids. Also, an optimum bowl and differential speed have a larger impact on the clarification results. Depending on the resulting centrifugal forces very fine solids can be separated assuring a low solid content of the insect fat.

\section{Wet processing technologies}

A completely different approach to recover protein-enriched meal, lipids and other fractions from insect larvae is wet or low temperature processing. In contrast to dry processing most of the water of the larvae is removed mechanically and only the separated fractions are dried afterwards. Especially for larger throughput capacities this is resulting in significant energy savings (Schmidt, 2019).

In the following an overview about the individual process steps for wet processing is provided focussing on relevant technologies to process insect larvae.

\section{Disintegration}

After the devitalisation stage (Section 3) a particle size reduction of the dead larvae needs to take place in wet processing. Insect lipid extraction from smaller particles is resulting in higher extraction yield and therefore lower residual fat content of the recovered protein-enriched meal (Horstmann, 2018).

\section{Grinding}

Grinders as depicted in Figure 11 which are commonly used in the fish and meat industry are suitable for this purpose. They have exchangeable hole plates which can be adjusted with different hole sizes for optimum fat extraction (Düpjohann, 1991).

Especially processing of wet products containing free water, lipids and proteins such as insect larvae is bearing the risk of creating emulsion when applying too much shear forces. Therefore, grinders should be operated with sharp knives and hole plates to cut the insect larvae and avoid squeezing. Moreover, high shear forces due to high speed cutters and mills for reducing the particle size of insect larvae often have the disadvantage of creating two much emulsion.

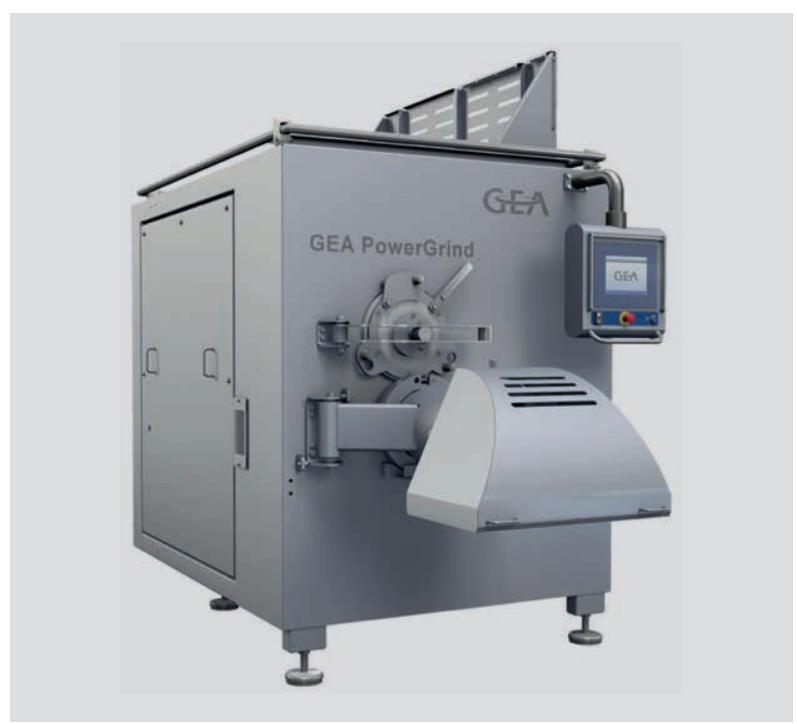

Figure 11. Grinder with exchangeable hole plates (right side) for particle size reduction (figure by GEA Food Solutions, Bakel, the Netherlands).

For small plants eccentric screw pumps with cutter and hole plate inside the pump housing (Figure 12) are available. These pumps enable cutting and conveying in one process step. Changing of knives and plates for re-sharpening takes more time compared with grinders designed for regular cleaning because such pumps need to be dismantled for this purpose. But relatively low capital expenditure can nonetheless be interesting for small capacity solutions.

\section{Soft separators}

In the meat, poultry and fish industry soft separators are used separating soft meat from harder shells or bones. A squeezing belt feeds the product towards a perforated rotating bowl and presses the soft components through the holes of the bowl. Harder components remain outside the drum. The ratio between yield and quality can be influenced by means of adjusting the pressure for squeezing the product against the bowl shell (Baader, 2020).

For processing of insect larvae, the same technology can be applied to separate the hard exoskeleton from the soft fraction containing water, proteins and lipids (Laurent $e t$ al., 2018). The soft fraction can be further processed like the minced larvae after the grinding stage and no further grinding is required.

The hard fraction, which is also called chitin fraction, can be further processed into chitosan. (Rumpold et al., 2017). Protein, which either sticks as soft part at the exoskeleton or is bound in it, is lost for the protein recovery process. Therefore, the use of a soft separator reduces the total amount of protein which could be recovered in the downstream process. 


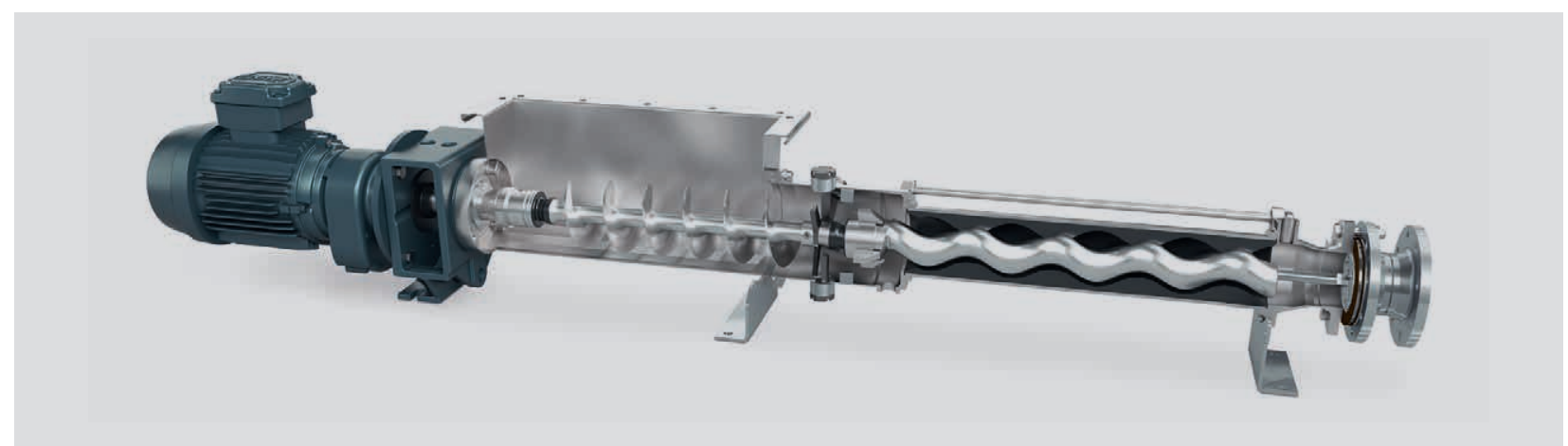

Figure 12. Eccentric screw pump with integrated cutting devices (Netzsch, 2020).

\section{Pre-treatment}

In order to mechanically separate the lipids from the water and solids fractions temperatures of around $80-95^{\circ} \mathrm{C}$ are recommended based on own practical experience. Arsiwalla and Aarts (2015) suggest temperatures between 70 and $100^{\circ} \mathrm{C}$. At temperatures above the melting point of insect fats separation already takes place. Lower temperatures preserve the functional properties of proteins. But due to lower fat yield and higher residual fat content in the solids fraction melting and separation take place at temperatures above $80^{\circ} \mathrm{C}$ in industrial applications.

Beside the temperature the retention time can have a significant influence on the extraction of lipids. For example, in the olive oil recovery processes where the socalled malaxing is important for sufficient oil extraction (Hamatschek, 2006), longer retention times at higher temperatures are favourable to extract the lipids from its cells under continuous and gentle mixing at low impeller speed avoiding emulsions. Horstmann (2018) and Kirchner et al. (2019) have demonstrated the correlation between retention time and fat yield and suggest retention times of up to 120 minutes especially for Tenebrio molitor. To achieve this, larger processing lines can have two or more retention tanks in parallel melting in one tank and drawing product from the another for continuous processing of the downstream line. A tubular heat exchanger should be considered for pre-heating the larvae prior to the retention tanks. Especially for larger processing capacities the heating up period can be shortened. For smaller wet processing systems, a semi-continuous batch heating might be a more economical solution.

For more efficient heat transfer pre-heating of the minced raw product via tubular heat exchanger should be considered especially for medium and large capacity lines (approx. 3-10 t/h).

Addition of some hot water could be necessary depending on the amount of liquids available in the raw material and selected separation technologies (Section 5 'Mechanical separation'). This is reducing the viscosity of the suspension for further mechanical separation and helps to de-fat effectively. Since additional water is increasing drying costs the addition of water should be minimised or eliminated if possible.

Adjustment of $\mathrm{pH}$ has also a significant influence on lipid separation. It has been demonstrated in extensive test series with T. molitor (Heidhues et al., 2020; Horstmann, 2018) how lower $\mathrm{pH}$ values (2-4) improve the creation of a larger lipid layer (by volume) compared with tests at higher $\mathrm{pH}$ values. Disadvantage of very low $\mathrm{pH}$ values are additional operating costs and the creation of salts because of acid to be added.

\section{Mechanical separation}

In wet processing of insect larvae, mechanical separation of the heated suspension containing lipids, water (from larvae and water added) and solids takes place mainly by using centrifuges which have different design features for the specific process stage being used for. In larger installations and especially when there is a focus on high quality of lipids recovered the combination of horizontal decanter centrifuges and vertical disc stack centrifuges is common.

\section{Three-phase separating decanter}

As outlined for lipid clarification in dry processing (Section 4 'Lipid separation') a clarifying decanter centrifuge separates the liquid phase from the solids phase according to differences in density continuously. For this two-phase suspension a 'liquid-solid' separation is required. In wet processing the suspension to be separated consists of at least one more phase since the water is not evaporated before separation (Figure 15). For this reason, a three-phase separating decanter for a 'liquid-liquid-solid' separation is commonly used for wet processing of insect larvae. While solid separation takes place like in a clarifying decanter described in Section 4 'Lipid clarification. 
Lipid clarification, lipids are separately discharged from the heavier water (in wet processing referred to as stickwater) according to different densities. Typical feed composition of two different samples of wet processed insect larvae are shown in Figure 13. The two liquid phases can be discharged separately as shown in the example in Figure 14.

To optimise the performance of a three-phase separating decanter the position of the separating zone can be adjusted by changing regulating rings or tubes for the heavy and light liquid discharge. This is required to minimise fat losses to the water or to reduce the amount of free water in the fat discharged to a minimum. Some centrifuge manufacturers offer systems for variable adjustment of the separating zone while the machine is in operation. This allows operators to fine tune the separation process and the insect fat yield and quality can be optimised without stopping the machine and changing parts.

For food grade solutions decanter centrifuges can be automatically cleaned with water, caustic and acid after a certain period or at the end of a production shift (Section 5 'Cleaning').

\section{Disc stack separator}

When the insect fat recovered needs to meet highest quality standards in terms of residual moisture and residual solids a disc stack separating centrifuge might be required to 'polish' the fat discharge of the decanter. Typically, stack

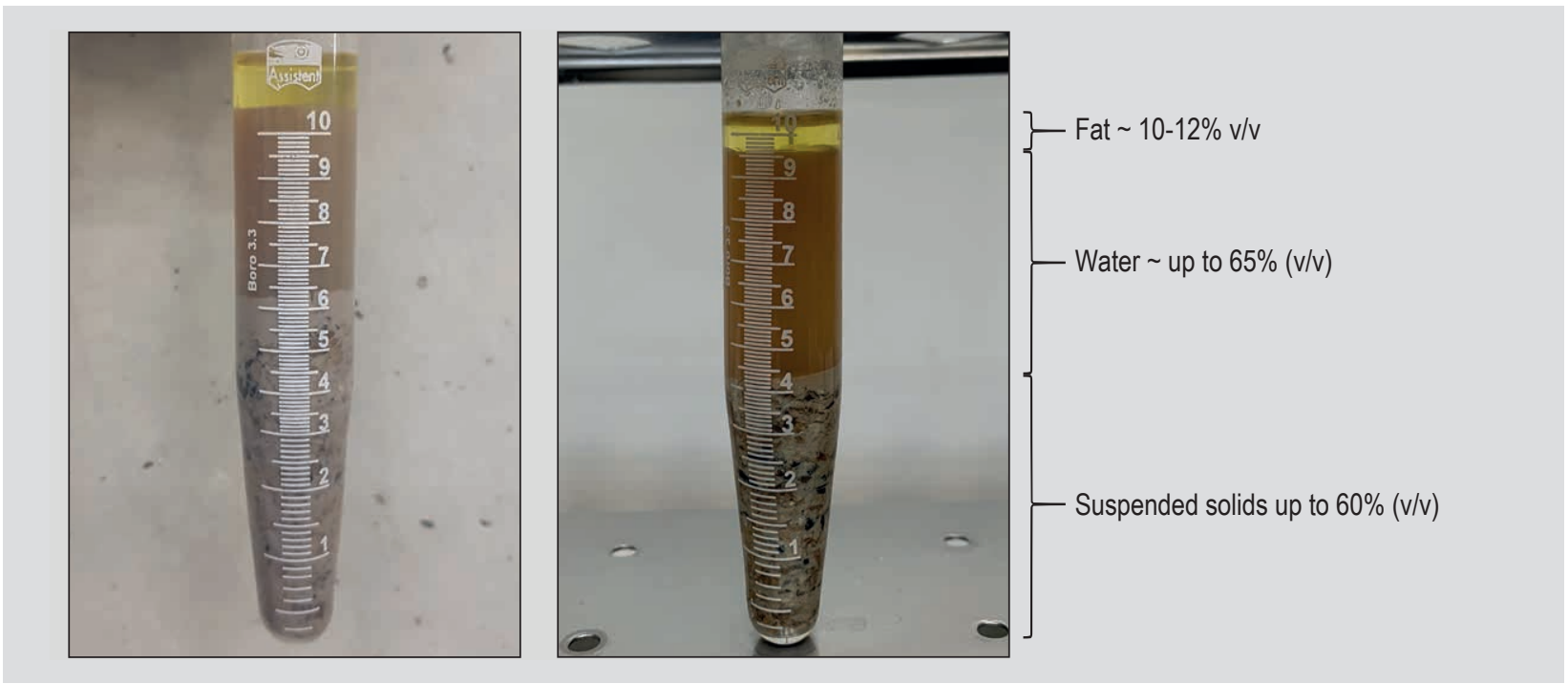

Figure 13. Typical spin test result of feed suspension to three-phase separating decanter centrifuge in wet insect larvae processing (figure by GEA Westfalia Separator GmbH, Oelde, Germany).

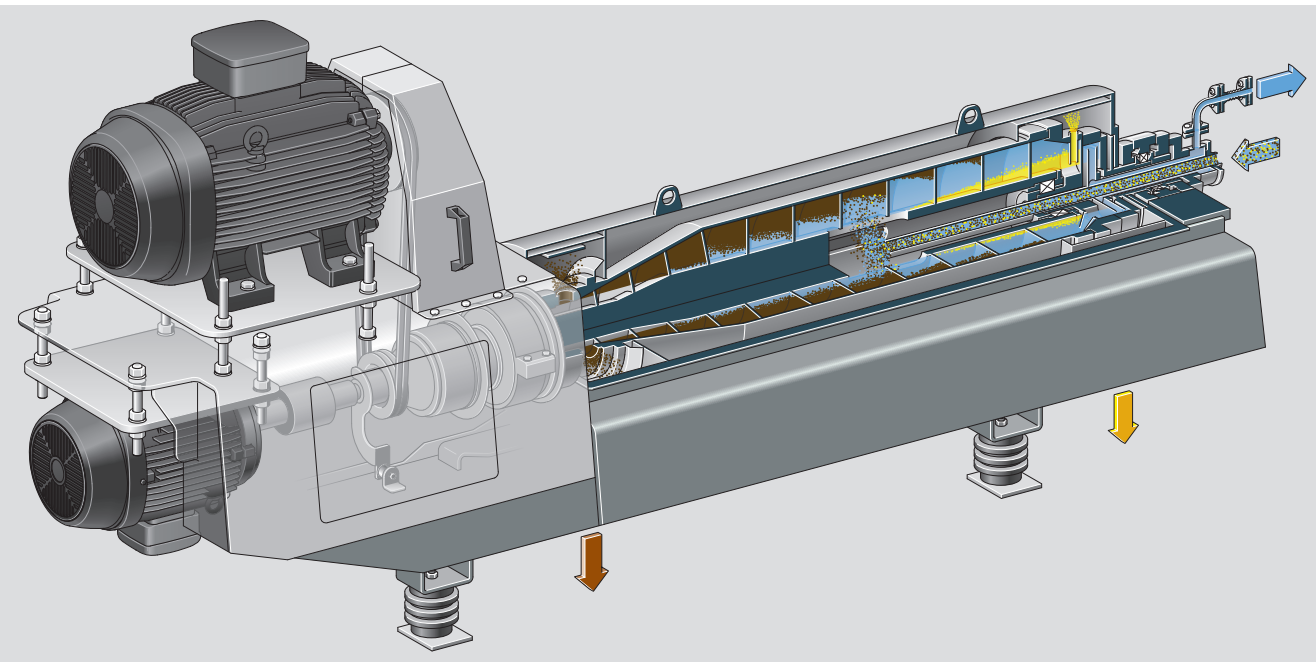

Figure 14. Three-phase separating decanter: Heated insect pulp fed into centrifuge is separated into solids (brown arrow), lipids (yellow arrow) and stickwater (blue arrow) phase (figure by GEA Westfalia Separator GmbH, Oelde, Germany). 
centrifuges are utilised for suspensions which much smaller content of solids (typically up to $2 \%(\mathrm{v} / \mathrm{v})$ ) than possible for decanters. Due to the very high centrifugal forces and the additional discs inside the bowl increasing the clarification area significantly relatively small machines can easily reach equivalent clarification areas of approx. 10,000-100,000 m².

As depicted in Figure 15, the suspension is fed into the rotating bowl and residual solids are collected in a solids holding space inside the bowl due to their higher density. Self-cleaning machines can discharge the collected solids discontinuously out of the rotating bowl into a collection cyclone by means of a water-operated hydraulic system.

Disc stack centrifuges for insect fat polishing are designed to separate the liquid fraction into a light (clean fat) and a heavy phase (stickwater) in addition to solids separation ('liquid-liquid-solids separation'). Separation takes place according to differences in density of all three phases as discussed regarding the principle of a three-phase separating decanter before. Like for a separating decanter the position of the separation zone can be adjusted to find the optimum separation regarding fat yield and quality.

\section{Concentration of stickwater}

As discussed before mechanical separation of free water is the major difference of wet processing compared with dry processing of insect larvae. Due to several processing and heating steps the water separated contains soluble solids including proteins and small amounts of residual lipids. Therefore, this fraction is called stickwater like in animal fat or fish oil recovery due to its gluing properties. Especially for larger larvae processing plants the stickwater should not be discharged to the wastewater system because of its relatively high biological oxygen demand and should be further processed instead. Including a stickwater concentration stage, dissolved proteins can be recovered improving the total protein yield of a wet processing line.

\section{Evaporation of the mechanically separated stickwater}

One technology commonly used in familiar applications like animal by-products processing or fish oil recovery is evaporation. Basically, the dry matter of the incoming stickwater from mechanical separation (Section 5 'Concentration of stickwater') is increased by water evaporation. Especially for larger processing lines (e.g. 5 ton larvae per hour and more) this is much more efficient than direct water evaporation inside the dryer (Section 5 'Drying of solids'). Concentrated stickwater can be added more easily to the solids dryer. The addition is recommended to make use of this valuable side-stream and therefore to improve the total protein yield of the final product.

Different technical principles for evaporation are used in the food and chemical industry. Compared with many other food applications water evaporation capacities

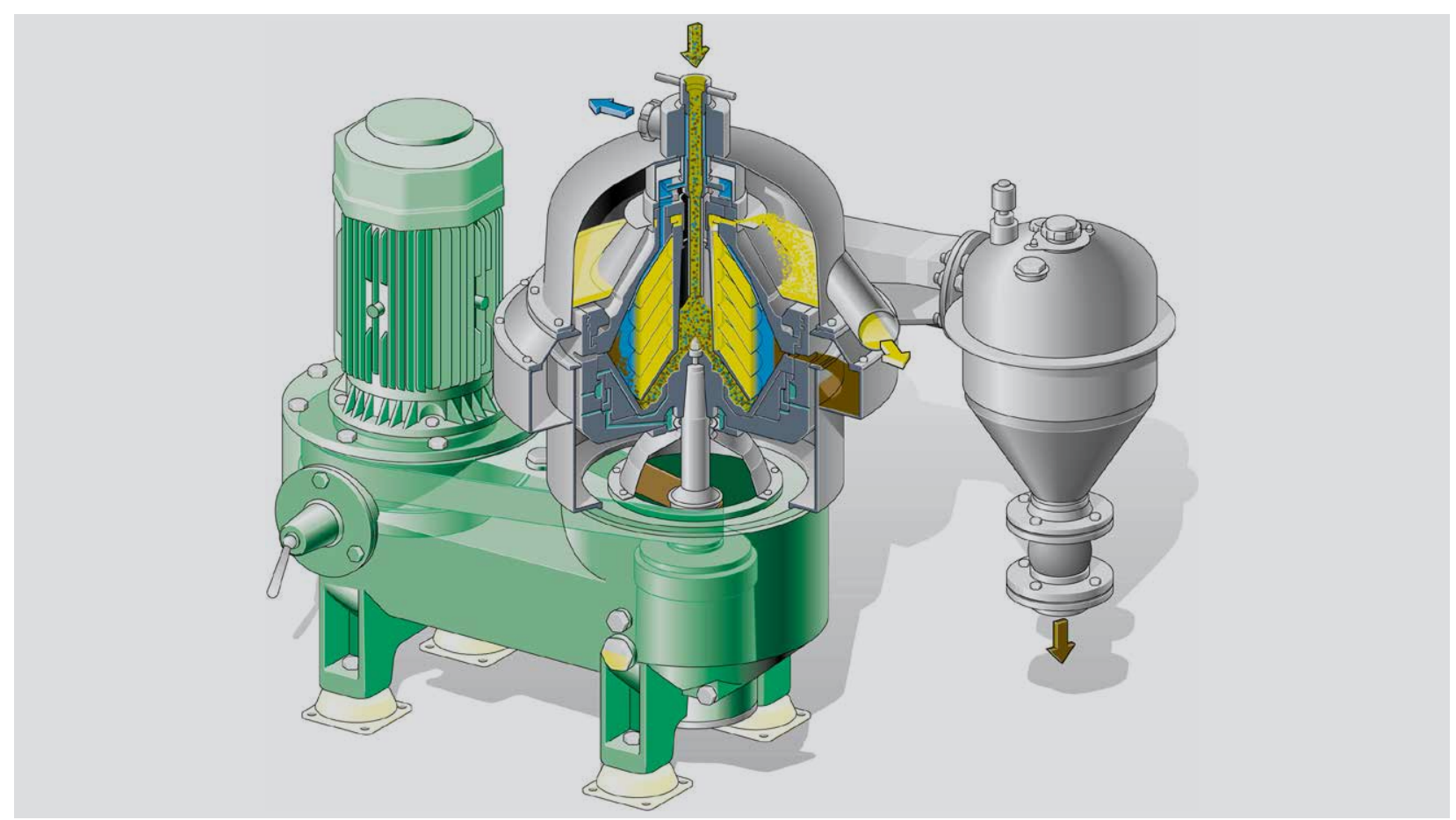

Figure 15. Self-cleaning disc stack separator: Insect fat containing residual water and solids is fed into the rotating bowl and is separated into clean fat (yellow arrow), stickwater (blue arrow) and solids (brown arrow) (figure by GEA Westfalia Separator GmbH, Oelde, Germany). 
required are still relatively low for insect larvae processing. For these small capacities a suitable design for the insect processing industry is a plate evaporator as illustrated in Figure 16.

In this system stickwater and heating media (hot water or steam) are transferred in counterflow through their relevant passages. Defined plate distances in conjunction with special plate shapes generate strong turbulence, resulting in optimum heat transfer. Intensive heat transfer causes the product to boil while the vapour formed drives the residual liquid, as a rising film, into the vapour duct of the plate package. Residual liquid and vapours are separated in the downstream centrifugal separator.

Plate evaporators are more sensitive to fouling between the plates and need to be opened for manual cleaning regularly especially for food grade applications.

Currently processing lines for larvae with a capacity of up to $10 \mathrm{t} / \mathrm{h}$ are considered as being quite large plants. For such plants and the resulting larger amount of stickwater to be processed falling film evaporators could be an alternative to be considered to the plate evaporators discussed.

A falling film evaporator consists of a vertical shell-and-tube heat exchanger with a separating section for concentrate and vapour at the bottom. The stickwater to be concentrated is supplied at the top of the heating tubes and distributed in such a way as to flow down the inside of the tube walls as a thin film. The liquid film starts to boil due to the external heating of the tubes and is partially evaporated as a result.

If e.g. a disc dryer is used to dry the de-fatted solids recovered after mechanical separation (Section 4 'Drying') the vapours collected from the dryer can be used to heat the falling film evaporator resulting in a very energy efficient solution. Another major advantage of this type of evaporator is its possible sanitary design especially for food grade applications. But due to its significant height and more complicated internal structure the capital expenditure is significantly higher than for more simple plate evaporators. If markets for insect products will grow in future and production plants with larger capacities are considered due to economies of scale falling film evaporators will become more interesting.

\section{Membrane filtration of the mechanically separated stickwater}

Another option for concentration of stickwater for further processing would be membrane filtration. Here the stickwater to be concentrated flows through filter elements made from material with defined pore size. Filter elements can be made from plastics or ceramic. Some of the water passes the membranes as permeate (filtrate). The collected stickwater concentrate which could not pass the membrane layer is called retentate.

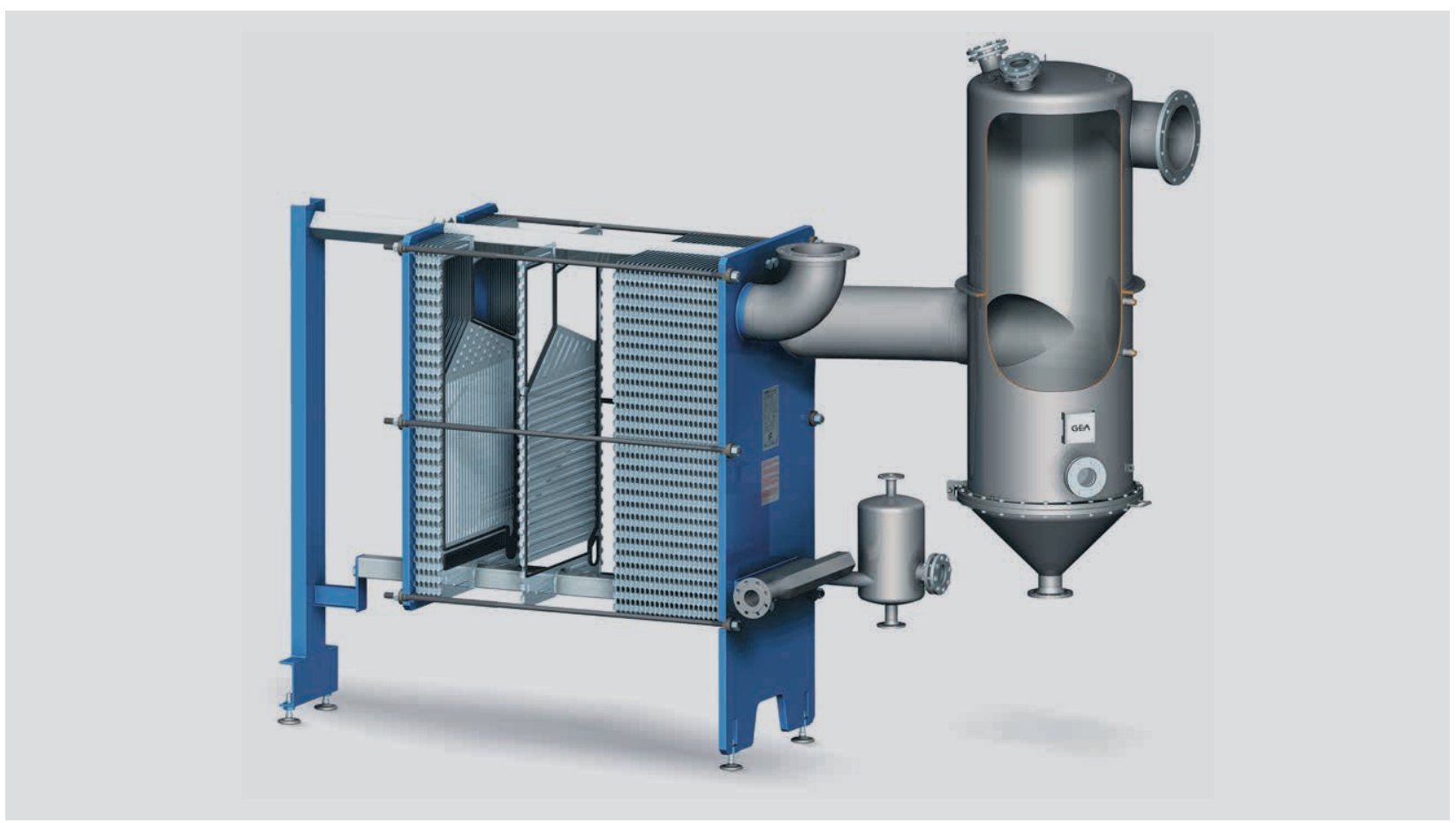

Figure 16. Plate evaporator (figure by GEA Wiegand GmbH, Karlsruhe, Germany). 
Especially because of fouling over a certain period of time this technology requires regular cleaning which can be made 'in place' (Section 5 'Cleaning'). As discussed for falling film evaporators membrane filtration will require larger capital expenditure and will only be interesting for larger quantities of stickwater to be concentrated. In addition, higher solid concentrations are possible for evaporators as concentrators for stickwater.

\section{Drying of solids}

Wet solids being collected during mechanical separation of the ground insects larvae (Section 5 'Mechanical separation') need to be stabilised by drying. Especially if the solids shall be used as ingredient for food applications drying to minimise microbiological problems needs to take place directly after mechanical separation of the solids. In general drying is a critical process step with strong impact on final product quality (Kröncke et al., 2018) and therefore also for feed purposes an important consideration. Properties like colour, smell, taste or structure can be influenced by drying.

All three dryer types discussed for dry processing (disc, fluidised bed and microwave dryer) can be used for drying of wet solids recovered by wet processing. Especially the disc dryer has been applied quite often since it is a common technology used in familiar industries like fish meal or animal by-products processing. Since these three dryers have been discussed in detail in Section 4 'Drying, two different air dryer types especially relevant for wet processing are presented for drying wet solids.

In general drying of solids after mechanical separation in wet processing is offering a high flexibility regarding the choice of dryers since the low-fat content does not create any problems for certain pneumatic dryers or mill dryers like full-fat meals can do.

\section{Ring dryer}

Ring dryers employ the basic principle that solids to be dried are conveyed through the dryer in a hot air stream. Particle size reduction can be provided by a disintegrator within the dryer. In this case no subsequent milling step like after drying in a disc dryer is necessary if the structure of the insect meal shall be a fine powder. Ring dryers incorporate a centrifugal classifier allowing selective internal recirculation of semi-dried solids, effectively lengthening the retention time of larger particles in the dryer, while finer material, which dries more rapidly, exits the dryer and gets directly into the cyclone. Figure 17 shows the principle of a ring dryer.

Compared to a fluidised bed dryer as discussed in Section 4 'Drying' this pneumatic type of dryer is requiring a lower

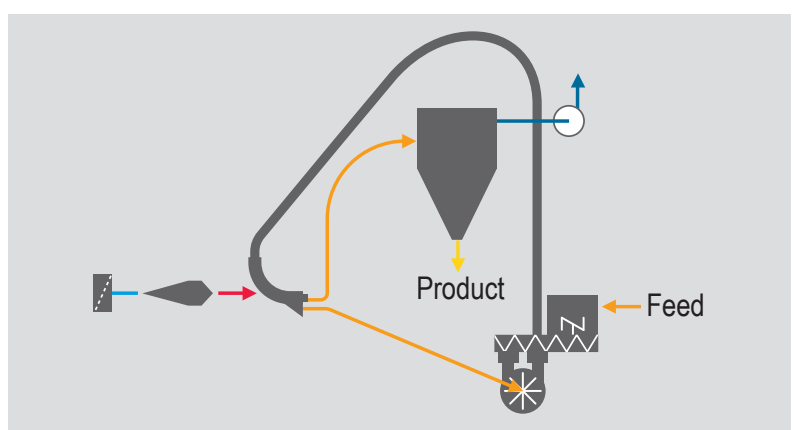

Figure 17. Schematic principle of ring dryer (GEA, 2020c).

capital expenditure both for the equipment and for the space required.

\section{Swirl Fluidiser ${ }^{\circledR}$}

If a more compact dryer with less height requirement than a ring dryer is needed a 'Swirl Fluidiser' (trademark of GEA) as shown in Figure 18 might be an option for insect meal producers.

The heated inlet air (e.g. directly heated by gas heater) enters a chamber where a swirl is created. The swirling air enters the drying chamber from the bottom. Wet solids are fed into the dryer by means of an agitated feed hopper and a screw conveyor. The agitator in the feed hopper is designed to de-lump the feed material and press it downwards into the screw conveyor. The feed enters the drying chamber at the upper part of a disintegrating rotor.

The fast-rotating disintegrating device, rotating vertically in the drying chamber, brakes up the feed. The dried fine product leaves the drying chamber in the top through a centrally mounted orifice. The dried solids are transported with the outlet air to a bag filter where they are discharged from the filter bottom cone by a rotary valve. The bag filter exhaust air is cleaned by a wet scrubber.

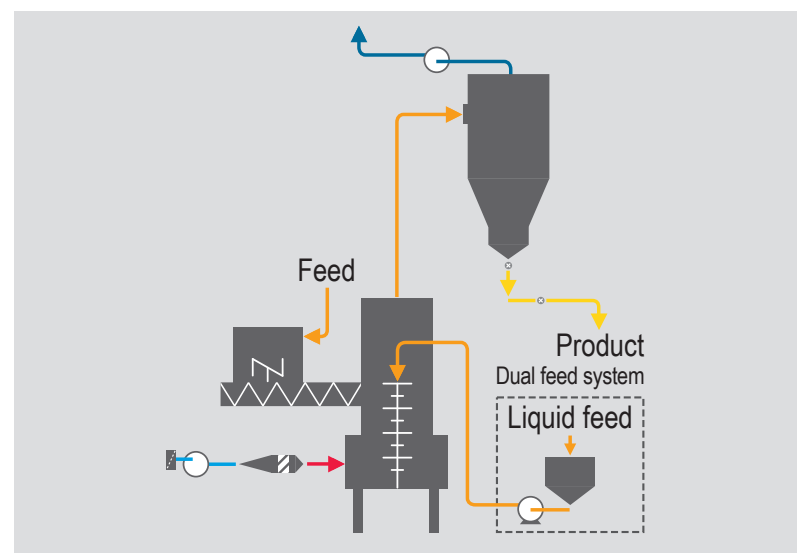

Figure 18. Schematic principle of a Swirl Fluidiser ${ }^{\circledR}$ (GEA, 2020c). 
Both energy consumption and capital expenditure are quite similar for the swirl fluidiser and the ring dryer. The more compact swirl fluidiser is suitable for smaller buildings.

\section{Cleaning}

Cleaning of equipment and complete process lines needs to be considered depending on the intended use of the insect meal. While dry processing will be often used for feed, wet processing is predestined for production of ingredients for food and for feed. Therefore, cleaning is of higher importance for wet processing technologies.

Especially for food applications safe products depend on effective cleaning of processing equipment. Cleaning also needs to be efficient so that cleaning times are reduced to a minimum to have the plant available for value adding production. Constant yield and product quality can be assured with efficient cleaning.

Hamatschek (2016) lists various factors for an effective cleaning. Chemical cleaning effects are achieved by using different cleaning media like caustic and acid. A typical sequence for a cleaning procedure includes a water rinse, followed by caustic rinse, intermediate water flushing, an acid rinse and finally another water flushing step. Temperature effects are important and need to be independently adjusted by heating for each cleaning step. Mechanical cleaning effects are achieved e.g. by flushing the equipment at appropriate flow rates. Time is to be considered for sufficient swallowing and removal of protein contending dirt particles. Finally, the mechanical design of the components to be cleaned need to be hygienic in terms of geometry and surface roughness. Optimised mechanical design and cleaning procedure helps reducing the amount of water and chemical used. This contributes to reduced water footprint and therefore is an important aspect in terms of sustainability.

Most equipment for wet processing except for the grinder can be cleaned in-place (CIP). The general industry understanding on the terminology is that CIP means a totally automatic cleaning sequence with no manual involvement. CIP systems can vary regarding their complexity starting from relatively simple stand-alone units with some manual controls up to fully automated systems with full cleaningin-place for the entire line. Once the optimum cleaning procedure has been set according to the factors mentioned above a highly effective and efficient cleaning with minimum downtime can be realised with a fully automated CIP. This can be a benefit regarding the operating costs. Because of additional tanks, pumps, valves and control technology including sensors the capital expenditure of a fully automated CIP system can be a significant factor.

\section{Comparison of dry and wet processing}

Both dry and wet processing technologies described within this overview have specific advantages depending on the required application and target markets and both systems have justified parallel existence. Dry processing and wet processing of larvae have been adapted from familiar applications like animal fat melting or fish oil recovery which have been applied for many decades. The equipment used for dry processing is available from familiar applications like animal by-products processing or vegetable oil recovery. In terms of the TRL (European Commission, 2019) all equipment used for the individual stages described within this work could be defined as 'TRL 9 ' ('proven systems in operational environment'). Reference installations from different suppliers have proven to be suitable for processing insect larvae, often larvae from BSF for the purpose of recovering protein meals for feed (GEA, 2020a).

In dry process systems most water of the processed larvae is evaporated before separation. Therefore, there is no stickwater after mechanical separation which needs to be processed or discharged. Especially for smaller capacities this can be an advantage because the higher energy input to evaporate most water in the dryer is less significant than at larger processing capacities.

By contrast during wet processing approx. $50 \%$ of the water of the processed larvae is removed by mechanical separation (three phase decanter) resulting in an increased energy efficiency compared with drying. Depending on local conditions regarding availability of heating media and energy costs, higher capital expenditure will be compensated by lower operating costs starting from throughput capacities for 3 to $5 \mathrm{t}$ larvae/h (Schmidt, 2019).

As described in Section 5 'Concentration of stickwater', stickwater from wet processing should be processed to add value to the protein meal, to increase the recovered protein yield and to avoid discharging a side-stream with a relatively high amount of dissolved protein (approx. 5\%) resulting in higher biological oxygen demand (BOD) if treated in waste water plants. Considering the lower amount of dissolved protein in condensate from dry processing vapours compared with stickwater from wet processing can be an advantage for dry processing.

For wet processing changes of different batches with intermediate cleaning can be done without major product losses. For the downstream dryer for drying the solids from mechanical separation this depends on the type of dryer used.

In general CIP is easier to achieve for wet processing. If meals and lipids shall be for food ingredients, cleaning 
is required and CIP needs to be considered (Section 5 'Cleaning').

Low process temperatures are important for high functionality of proteins and light lipid colour (Kröncke et al., 2018). This is relatively easy to achieve with wet processing. For dry processing special dryers and presses need to be selected if these factors need to be improved.

\section{Chitin extraction}

Chitin is included in the solids fraction separated by dry or wet processing. Removing the non-digestible chitin not only increases the protein content but also the digestibility of the finished insect meal. Chitin is a raw material for further processing, e.g. chitosan production. Therefore, removing the chitin can increase the value of the finished meal but also be an interesting by-product for additional value adding.

\section{Mechanical separation}

In Section 5 'Disintegration' the possibility of using a 'soft separator' has been presented.

For processing of insect larvae, the same technology applied e.g. for bone separation in the meat industry or hard-shell separation for shrimps can be applied to separate the hard exoskeleton from the soft fraction (Laurent et al., 2018). The hard fraction separated by a soft separator is containing the chitin where it is bound to skleroprotein (Rumpold et al., 2017). As a result, the overall protein recovery yield is slightly reduced while the finished meal is higher in protein content.

\section{Enzymatic hydrolysis}

Another way of removing the chitin from the protein and lipid phases is enzymatic hydrolysis. In contrast to well established chemical extraction this is an environmentally safe biological extraction using proteases (Rumpold et al., 2017). After mincing of the larvae and addition of water, enzymes are added. Due to enzymatic hydrolysis most protein is dissolved in the water phase.

In the following a two-stage mechanical separation takes place. By adjusting the bowl speed, the first decanter centrifuge is 'classifying' only the heavy chitin fraction from the suspension containing dissolved but also some lighter insoluble protein. At relatively low centrifugal acceleration, the chitin is discharged as solid phase and the rest of the suspension including soft solids via the liquid phase discharge. In the second stage, a three-phase separating decanter is separating lipids, liquid protein solution and suspended solids containing protein.
The chitin phase recovered after mechanical separation is containing nearly no protein which in turn is resulting in low protein losses. On the other hand, a much more complex processing is required resulting in higher capital expenditure.

\section{Scaling-up of process lines}

For producers of insect meals and other insect products scaling-up is an important consideration. According to the systematic of Hamatschek (2016) to get an innovative product from an idea to an industrial production the following steps are necessary:

- lab scale trials ('test kitchen');

- test plant trials;

- pilot production;

- industrial production.

To devise a business plan very small size tests in a lab can help to determine the right process conditions and can result in an estimated mass balance which is necessary to get the economics right.

It is recommended to verify these recipes in test plants where test equipment with similar technology used for the production later on is available. When doing pilot tests, the maximum throughput for the corresponding equipment at acceptable results in terms of qualities and yields achieved should be tested to be able to scale-up to an economical feasible solution. For example, in wet processing scalability from very small test production volumes in pilot plants to larger processing capacities of up to $10,000 \mathrm{~kg} / \mathrm{h}$ is relatively accurate. Since centrifuges play a major role in this wet processing, scale up factors from very small units up to larger production machines are typically higher than in other technologies like filtration.

A challenging question is the logistics for living larvae to be transported to process test centres of suppliers. In dry processing also dried larvae can be tested to scale-up e.g. presses which can make logistics much easier regarding testing.

For new products, pilot plants are reducing technical risks before larger industrial production of new products. This is to verify the economics estimated during the first development tests. Very helpful is also the production of small test batches to recover some product to be tested and verified. Many suppliers offer pre-engineered modular pilot plant solutions to limit capital expenditure.

When all steps have been passed successfully both the insect meal producer and the supplier of equipment have a relatively high security to be successful in large scale industrial production. Especially for the relatively young 
insect industry this should be considered for new product ideas, e.g. new ingredients for food.

\section{Automation}

When it comes to production lines for recovery of de-fatted insect meal as described for both dry and wet processing the level of automation becomes an important consideration. While small pilot plants can still be operated to a large extend manually a continuously operated process line needs a much higher degree of automation especially if only one to two operators have to run the complete line. Personal cost are one of the main drivers of production costs (Veldkamp et al., 2012).

In general, all technologies discussed within this overview could be operated as stand-alone units. Each process stage could have its own independent electrical control unit. Especially for smaller lines which might be changed in their near future regarding set up or regarding some further adaptions of additional equipment this might be economically sensible.

Equipment in modern production lines are often liked to process control systems controlling the entire plant. Connections can be made via bus systems or other networks, e.g. ethernet. This allows flexible adoptions of the control system in case of future changes. But more important the entire process is controlled via a central system allowing the operator to have good control over qualities and yields achieved. Process data can be easily accessible for remote display or even control if required. Remote maintenance systems can be implemented reducing operating expenditure in the long term because of optimised maintenance schedules and limited number of unplanned downtimes of the line.

Automation is also an relevant consideration for cleaning of complete processing lines, especially for wet processing. Automation of the cleaning process ensures repeatability, allows validation and minimises downtime (Section 5 'Cleaning').

In future digitalisation will most probably become more important. For insect meal producers this can be interesting not only for insect farming but also for further processing, e.g. production of low-fat meals and insect fats. This might contribute to higher product qualities and efficiencies in the entire value chain.

Some research projects are looking into the possibilities for such digital technologies (IFF, 2020). An important driver is suitable sensor technology to measure the relevant values online and to optimise processes based on optimised algorithms accordingly. Especially near infrared spectroscopy (NIR) could be a vehicle to measure different relevant data like protein content, moisture, fat content, etc. This can not only help to harvest larvae at their optimum age but also to optimise the process technology for downstream processing accordingly (IFF, 2020). Research work carried out at a German vegetable oil processor has shown the significance of such technologies to optimise processes and in future to self-optimise processing systems based on online measurement solutions like NIR (Rumrich, 2020).

\section{Outlook}

Even though technology readiness levels for insect larvae processing are high today, the permanent market pressure and consequently the need for more economical and sustainable solutions for producers of insect meals and lipids will most likely result in further technical developments. Incremental innovations will probably play a bigger role for developing the technology for this growing industry than disruptive new and completely different technologies. Especially in the field of process automation and digitalisation existing technologies already used in familiar industries might play a larger role for insect meal producers in future than today. Technologies like NIR might contribute to optimum process control and therefore higher product qualities or increased yields for producers.

For food applications processed insect larvae added as meals or lipids to specific recipes will probably open markets for larger volumes. Unless for niche markets, higher acceptance for products with neutral ingredients in terms of e.g. smell and colour is expected than for products where insect origin can be recognised (Sindermann, 2019a). De-fatted meal with low fat content will be preferred by food and feed producers to adjust required fat contents easily. More sanitary design of processing systems including automated cleaning systems will be required when markets will be ready for de-fatted insect meals and fats as ingredients for the food industry.

\section{Conclusions}

Technologies for industrial production of de-fatted insect meal including insect lipids and chitin have been adapted from familiar applications and further developed for the specific needs of this industry. Both processing types, dry and wet processing, have their individual advantages for different industrial applications. For smaller and medium larvae processing capacities dry processing is often more economical. For larger capacities, wet processing has got energetic advantages because of mechanical separation of most of the water which as a consequence does not have to be evaporated directly.

All technologies discussed are used for insect larvae processing in reference plants or are used in very familiar 
applications and have been tested in pilot operations for insect larvae. Currently most plants for de-fatting of insect larvae are processing larvae for feed production, e.g. larvae of BSF (GEA, 2020a). For high product qualities of the recovered protein meals gentle drying technologies are available.

If in future de-fatting is requested more often for production of food ingredients depending on local legislation, foodgrade design and cleaning of processing equipment becomes an important consideration for producers of such insect meals. Wet processing systems are relatively easy to clean and all equipment except the grinder for disintegration can be cleaned-in-place.

For some technologies discussed economies of scale require larger production volumes than most systems being in operation today. This has been shown e.g. for technologies like evaporation in wet processing.

Even though the insect industry will probably come up with many new product innovations within the next time, the major technologies for dry and wet processing are ready to be applied. Most equipment will be ready for use with minor adjustments and after pilot testing production of new products will be ready relatively quickly if marked market demand increases.

\section{Conflict of interest}

The authors declare no conflict of interest.

\section{References}

Arsiwalla, K. and Aarts, K., 2015. Method to convert insects and worms into nutrient streams and compositions obtained thereby. Patent: WO2014123420 A1. Available at: https://patents.google.com/patent/ WO2014123420A1/en?oq=WO2014123420+A1.

Baader, 2020. What is Baader Meat? Nordischer Maschinenbau Rud. Baader GmbH+Co.KG, Lübeck, Germany. Available at: https:// www.baader.com/en/products/separator_processing/.

Baltes, W. and Matiseek, R., 2011. Lebensmittelchemie, 7. Vollständig überarbeitete Auflage. Springer, Heidelberg, Germany.

Barragan-Fonseca, K.B., Dicke, M. and Van Loon, J.J.A., 2017. Nutritional value of the black soldier fly (Hermetia illucens L.) and its suitability as animal feed - a review. Journal of Insects as Food and Feed 3: 105-120.

Böschen, V., 2018. Comparison of wet and dry processing and fractionation for mealworms (Tenebrio molitor). Insecta Conference 2018. Gießen, Germany.

De Jong, B., 2018. Not to be a pest: why insects are gaining popularity as feed and food. RaboResearch, Rabobank, Utrecht, the Netherlands.

Düpjohann, J., 1991. Centrifuges, decanters and processing lines for the recovery of edible fat. Technical-scientific documentation no. 15, Westfalia Separator AG, Oelde, Germany
European Commission, 2019. HORIZON 2020 - work programme 2018-2020. European Commission Decision C(2019)4575 of 2 July 2019. European Commission, Brussels, Belgium.

GEA, 1999. Decanters and separators for industrial fish processing. GEA Westfalia Separator Industry, Oelde, Germany.

GEA, 2020a. GEA explores potential of insect protein for animal feed. GEA, Düsseldorf, Germany. Available at: https://www.gea.com/en/ stories/gea-explores-potential-of-insect-protein-for-animal-feed.jsp. GEA, 2020b. Fluid bed dryer (static). GEA, Düsseldorf, Germany. Available at: https://www.gea.com/en/products/dryers-particleprocessing/fluid-beds/fluid-bed-dryer.jsp.

GEA, 2020c. GEA drying and particle formation technologies. GEA, Düsseldorf, Germany. Available at: https://www.gea.com/en/ binaries/drying-spray-atomizer-fluid-bed-particle-formationchemical-gea_tcm11-34869.pdf.

Haarslev, 2020. Disc dryer for continuous drying of de-fatted fish, animal or poultry by-products. Haarslev, Søndersø, Denmark. Available at: https://haarslev.com/products/disc-dryer-2/.

Halloran A. and Vantomme P., 2013. The contribution of insects to food security, livelihoods and the environment. Food and Agriculture Organization of the United Nations, Rome, Italy. Available at: http:// www.fao.org/3/i3264e/i3264e00.pdf.

Hamatschek, J., 2016. Lebensmitteltechnologie. Eugen Ulmer, Stuttgart, Germany.

Heidhues, J., Kirchner, S. and Sindermann, D., 2020. Method for obtaining products for the food industry and/ or feed industry from insects and solid phase obtained from insects. Patent: WO 2020 / 011903 A1. Available at: https://patents.google.com/patent/ WO2020011903A1/en.

Horstmann, N., 2018. Optimierung des Nassextraktionsverfahrens für die Verarbeitung von Insekten. BSc thesis, University of Applied Sciences, Osnabrück, Germany.

Internationale Forschungsgemeinschaft Futtermitteltechnik e.V. (IFF), 2020. Optimierung der Aufbereitung von Mehlkäferlarven (Tenebrio molitor) und daraus resultierender Produkte durch eine automatisierte Prozessführung auf Basis eines nichtinvasiven Nahinfrarot-Messsystems. IFF, Braunschweig, Germany. Available at: https://www.iff-braunschweig.de/insekten/.

International Platform of Insects for Food and Feed (IPIFF), 2018. The European insect sector today: challenges, opportunities and regulatory landscape. IPIFF, Brussels, Belgium.

International Platform of Insects for Food and Feed (IPIFF), 2019. Guide on good hygiene practices for European Union (EU) producers of insects as food and feed. IPIFF, Brussels, Belgium. Available at: https://ipiff.org/wp-content/uploads/2019/12/IPIFFGuide-on-Good-Hygiene-Practices.pdf.

Kröncke, N., Böschen, V., Woyzichovski, J., Demtröder, S. and Benninga, R., 2018. Comparison of suitable drying processes for mealworms (Tenebrio molitor). Innovative Food Science and Emerging Technologies 50: 20-25. https://doi.org/10.1016/j. ifset.2018.10.009 
Laurent, S., Sarton Du Jonchay, T., Levon, J.-G., Socolsky, C., Sanchez, L., Berezina, N., Armenjon, B. and Hubert, A., 2018. Method for treating insects in which the cuticles are separated from the soft part of the insects using a belt separator, Patent: WO 2018 / 122353 A1, Available at: https://patents.google.com/ patent/WO2018122475A1/en.

Leanarts, S., Van der Borght, M., Callens, A. and Van Campenhaut, L., 2018. Suitability of microwave drying for mealworms (Tenebrio molitor) as alternative to freeze drying: impact on nutritional quality and colour, Food Chemistry 254: 129-136.

M Miles Global, 2020. Pressure filter leaf vertical \& horizontal. B Miles Global Co., Ltd., Pathum Thani, Thailand. Available at: https:// www.bmiles-filtration.com/product/pressure-filter-leaf-verticalhorizontal/.

Netzsch, 2020. NEMO BO/SO hopper pump with cutting device. Netzsch, Dorchester, UK. Available at: https://pumps.netzsch. com/en/products-accessories/nemo-progressing-cavity-pump/ boso-with-integrated-cutting-device/.

Reinartz, 2020. Insect proteins from sustainable production. Reinartz, Neuss, Germany. Available at: https://www.reinartz.de/en/insectproteins/.

Rumpold, B., Bussler, S., Jäger H. and Schlüter, O., 2017. Insect processing. In: Van Huis, A. and Tomberlin, J. (eds.) Insects as food and feed - from production to consumption. Wageningen Academic Publishers, Wageningen, the Netherlands, pp. 319-342. Rumrich, F., 2020. Comparative evaluation of near and mid infrared spectroscopy in the control of process engineering processes. University of Applied Sciences Südwestfalen, Meschede, Germany.
Schmidt, J., 2019. Vergleich von Herstellkosten unterschiedlicher Verfahren zur Gewinnung von Protein und Fett aus Insektenlarven. Project Assignment, University of Applied Sciences Südwestfalen, Meschede, Germany.

Sindermann, D., 2019a. The insect revolution: too hard to swallow? Generate 19: 28-31. Available at: https://www.gea.com/en/binaries/ generate-magazine-19_tcm11-52635.pdf.

Sindermann, D., 2019b. First experience with processing insects. EFPRA Congress 2019, Technical Symposium, June 13, 2019, European Fat Processors and Renderes Association (EFPRA), La Baule, France.

Van den Bossche, M. and Van Vaerenbergh, G., 2014. Microwave drying: a more efficient technology than gas-stirpping. GEA, Düsseldorf, Germany. Available at: https://www.gea.com/en/stories/ microwave-drying.jsp.

Van Huis, A. and Tomberlin, J., 2017. Insects as food and feed - from production to consumption. Wageningen Academic Publishers, Wageningen, the Netherlands.

Van Huis, A., Van Itterbeeck, J., Klunder, H., Mertens, E., Halloran, A., Muir, G. and Vantomme, P., 2013. Edible insects: future prospects for food and feed security. FAO Forestry Paper 171, FAO, Rome, Italy. Veldkamp, T., Van Duinkerken, G., Van Huis, A., Lakemond, C.M.M., Ottevanger, E., Bosch, G. and Van Boekel, M.A.J.S., 2012. Insects as a sustainable feed ingredient in pig and poultry diets - a feasibility study. Wageningen UR Livestock Research, Wageningen, the Netherlands. 
